\title{
La responsabilidad contractual en torno al artículo 1945 del Código Civil chileno (artículo 2003 Código Civil colombiano)*
}

\author{
Recibido: 23 de enero de 2018 • Aprobado: 15 de junio de 2018 \\ https://doi.org/10.22395/ojum.v18n36a5
}

Andrés Erbetta*

\begin{abstract}
RESUMEN
En este trabajo se analiza dogmáticamente el artículo 1945 del Código Civil chileno (2003 del Código Civil de Colombia) con el objeto de establecer la función que cumple la culpa en dicho precepto, el alcance de la indemnización de perjuicios y las causales de exoneración en el contrato de arrendamiento, para finalizar con un análisis sobre la opción de remedios a la luz de dicho precepto. A partir de esta indagación, el autor concluye que la culpa debe entenderse referida al incumplimiento contractual de las obligaciones del arrendatario. Del mismo modo, descarta que la culpa, entendida como el reproche a la conducta del deudor, constituya un elemento de la responsabilidad contractual.
\end{abstract}

Palabras clave: incumplimiento contractual; naturaleza de los perjuicios; opción de remedios.

\footnotetext{
Este trabajo tiene su origen en el capítulo Acerca de las funciones de la diligencia y la culpa en la responsabilidad contractual. Intento de relectura con miras a desentrañar el sentido y alcance de la regla sobre la carga de la prueba del artículo 1547 inc. 3, de la tesis doctoral en que se encuentra trabajando el autor en el programa de Doctorado en Derecho de la Universidad de los Andes, Santiago, Chile, titulada La responsabilidad contractual y la carga de la prueba del incumplimiento en el Código Civil chileno, dirigida por el profesor doctor Jorge Baraona González. Para esta publicación se ha agregado nueva bibliografía y jurisprudencia.

** Abogado, Universidad Diego Portales, Santiago, Chile, magíster en Derecho Privado, Universidad de los Andes, Santiago, Chile. Alumno regular del programa de Doctorado en Derecho de la Universidad de los Andes, Santiago, Chile. Correo electrónico: aerbettamattig@gmail.com
} 


\title{
Contractual Responsibility According to Article 1945 of the Chilean Civil Code (2003 Colombian Civil Code)
}

\begin{abstract}
In this paper, Art. 1945 of the Chilean Civil Code (2003 of the Colombian Civil Code) is dogmatically analyzed to determine the function fulfilled by the notion of negligence in that provision, and the scope of the indemnification of damages and the causes of exoneration in the lease agreement, to end with an analysis on the option of remedies in light of said precept. Based on this research, it is concluded that fault must be understood as referring to the contractual breach of the obligations of the lessee. In the same way, it is discarded that guilt, understood as the reproach to the behaviour of the debtor, constitutes an element of contractual responsibility.
\end{abstract}

Keywords: breach of contract; damages nature; solution options.

\section{A responsabilidade contratual em torno do artigo 1945 do Código Civil chileno (artigo 2003 do Código Civil colombiano)}

\section{RESUMO}

Neste trabalho analisa-se dogmaticamente o artigo 1945 do Código Civil chileno (2003 do Código Civil da Colômbia) com o objetivo de estabelecer a função que a culpa cumpre em tal preceito, o alcance da indenização de prejuízos e as causais de exoneração no contrato de locação, para finalizar com uma análise sobre a opção de soluções à luz de tal preceito. A partir dessa indagação, o autor conclui que a culpa deve ser entendida com respeito ao incumprimento contratual das obrigações do arrendatário. Do mesmo modo, descarta que a culpa, entendida como reprovação à conduta do devedor, constitua um elemento da responsabilidade contratual.

Palavras-chave: incumprimento contratual; natureza dos prejuízos; opção de soluções. 


\section{INTRODUCCIÓN}

El artículo 1945 del Código Civil chileno (CCCh), ubicado en el párrafo $3^{\circ}$ del Libro IV, sobre las obligaciones del arrendatario en el arrendamiento de cosas, señala:

Cuando por culpa del arrendatario se pone término al arrendamiento, será el arrendatario obligado a la indemnización de perjuicios, y especialmente al pago de la renta por el tiempo que falte hasta el día en que desahuciando hubiera podido hacer cesar el arriendo, o en que el arriendo hubiera terminado sin desahucio. Podrá con todo eximirse de este pago proponiendo bajo su responsabilidad persona idónea que le substituya por el tiempo que falte, y prestando al efecto fianza u otra seguridad competente.

Los orígenes de esta disposición -que en idénticos términos recoge el artículo 2003 del Código Civil colombiano (CCCo) - parecen encontrar acomodo en el artículo 1760 del Código Civil francés (CCFra), que señala: "En caso de resolución por culpa del arrendatario, éste deberá pagar el precio del alquiler durante el tiempo necesario para volver arrendar, sin perjuicio de la indemnización por daños y perjuicios que hayan podido resultar del abuso". Con todo, no existe una nota de Bello que aclare cuáles fueron los antecedentes que consideró para su establecimiento. De hecho, el precepto recién aparece en el artículo 2124 b. del proyecto inédito de Código Civil, que antecedió a la compilación civil definitiva.

Existen buenas razones para detenerse en el estudio de esta regla. Prima facie, su tenor literal -que en forma expresa refiere a la terminación por culpa del arrendatario- pareciera constituir un obstáculo para la tendencia objetivadora del derecho de contratos, construida sobre una noción de incumplimiento desprovista del reproche subjetivo como factor de imputación, circunstancia agravada por la relevancia que tiene el arrendamiento en el tráfico jurídico.

Por otra parte, si tomamos en cuenta que un sector de la doctrina confina la indemnización de perjuicios a los daños que exceden del valor de la prestación, es necesario aclarar cuál es la naturaleza jurídica del pago de la renta, considerando que esta disposición parece incardinarla, especialmente, como una partida indemnizatoria, según reza su inciso $1^{\circ}$.

Finalmente, como esta norma permite al arrendatario proponer a un tercero que lo sustituya durante todo el período que falte -no obstante la terminación provocada por el arrendatario-, existe base para sostener que el deudor puede forzar la pervivencia del contrato en contra de la voluntad del acreedor, lo que va a contrapelo del derecho a la opción de remedios que la doctrina más reciente atribuye al acreedor insatisfecho. 
En fin, para acometer esta tarea, se analizarán los problemas interpretativos que surgen de esta disposición, para luego profundizar en las propuestas de solución que se formularán respecto de cada uno de ellos. El trabajo finalizará con nuestras conclusiones.

\section{LOS PROBLEMAS DE INTERPRETACIÓN QUE SURGEN A PARTIR DEL ARTíCULO 1945 (ARTíCULO 2003)}

\subsection{Conclusiones provisionales que surgen a partir del texto del artículo 1945 (artículo 2003)}

Como anticipamos, una lectura rápida de esta disposición pareciera asentar tres ideas.

La primera es que la culpa constituye uno de los presupuestos de la responsabilidad contractual del arrendatario. Así resultaría del tenor expreso del artículo 1945 (artículo 2003), cuyo supuesto de hecho se apoya, precisamente, en la terminación culpable del arrendamiento.

Esta consecuencia no tendría nada de peculiar, tomando en consideración que, para un vasto sector de la doctrina, tanto chilena como colombiana, el fundamento de la responsabilidad del deudor se construye, precisamente, sobre la base del incumplimiento culpable de sus obligaciones. En este sector se encuentran autores chilenos como Alessandri (1930) y Claro Solar (1937), quienes sostienen que la infracción contractual, para dar lugar a los perjuicios, debe ser imputable al deudor, lo que significa que esta debe provenir de un hecho suyo, como la culpa o el dolo. En Colombia estas conclusiones también son apoyadas por autores como Uribe-Holguín (1979), Tamayo (1990) y Ospina (2016). Precisamente por esta razón, Cortés (2009) afirma que la regla de clausura del sistema la constituyen la culpa y el dolo.

La segunda reflexión refiere al alcance de la indemnización. Nuevamente, si solo atendemos a la literalidad del precepto, deberíamos concluir forzosamente que, una vez producida la terminación culpable del contrato, el arrendatario resulta obligado a indemnizar al arrendador, dentro de cuyas partidas se encuentra el pago de la renta "por el tiempo que falte hasta el día en que desahuciando hubiera podido hacer cesar el arriendo, o en que el arriendo hubiera terminado sin desahucio". Ya se dijo: la razón de lo anterior estriba en que el precepto previene en forma expresa que el arrendatario es obligado a la indemnización y, especialmente, al pago de la renta, lo que parece dar a entender que esta última forma parte de los daños causados por la infracción contractual.

Con respecto a lo anterior, cabe señalar que, en el contexto más amplio de la responsabilidad contractual del deudor, diversos autores plantean la teoría de la unidad del fenómeno resarcitorio, conforme a la cual tanto el equivalente pecuniario o aestimatio rei (valor de reemplazo de la prestación incumplida) como los daños por sobre dicho 
valor o id quod interest, constituyen una unidad indivisible, que se rige por las mismas normas y principios. Así se ha planteado en Chile con autores como López (2015); en España se puede citar a Cristóbal Montes (1989), a Capilla (1989) y, en Colombia, a García (2014). Este último, por ejemplo, sostiene que el no pago de una obligación configura la consumación de un perjuicio en la modalidad de daño emergente, el cual se indemniza con el pago del valor pecuniario de la obligación incumplida. Pero como ese pago es extemporáneo, también va acompañado del monto de los perjuicios moratorios y extrapecuniarios, si estos se hubieren causado. De este modo, concluye García, el fundamento de la responsabilidad es mixto. Por una parte, se estructura sobre su función esencial, que es la indemnizatoria:

Pero el cumplimiento efectivo de esa función desencadena el efecto paralelo de satisfacer el derecho crediticio que se le conculcó al acreedor, pues con el cambio de objeto al que se vio precisada su acreencia inicial y con la solución íntegra de ese nuevo objeto, cualquier obligación del deudor con el acreedor queda extinguida por el pago, lo que se traduce en la satisfacción del derecho de crédito (2014, p. 90).

Finalmente, la tercera deducción que se puede extraer del precepto en cuestión es que aun a pesar de la terminación del contrato, nada impediría que el arrendatario culpable proponga al arrendador a una persona idónea que lo substituya por el tiempo que falte, lo que determinará, en definitiva, que el contrato subsistirá, incluso contra la voluntad del arrendador, ahora con un tercero que ocupará el lugar jurídico que originalmente correspondía al arrendatario.

Lo anterior tampoco sería una rareza dentro del pensamiento más extendido del derecho de los contratos chileno. Existen hipótesis en las que si bien es el acreedor quien tiene la llave del sistema de remedios, quien cierra la puerta es el deudor. Así ocurre con la resolución del contrato bilateral, donde diversos autores plantean que una de las consecuencias de la necesidad de sentencia judicial que la declare es, precisamente, que el deudor puede enervar la acción resolutoria con el pago de la prestación demandada, lo que redunda en la subsistencia de la relación contractual, aun cuando el acreedor insatisfecho haya instado por la disolución del vínculo contractual y su liquidación. Entendida de este modo, la decisión sobre la continuidad del contrato queda entregada al deudor, aun cuando el artículo 1489 (1546 en el CCCo) ponga la opción en el contratante cumplidor. En este espectro, por nombrar algunos, se ubican autores como Alessandri (1930), Fueyo (1958) y Abeliuk (2001). Además, esta perspectiva del derecho de opción que aparenta ofrecer el artículo 1945 (2003) congenia perfectamente con la idea de que los contratos se celebran para cumplirse, lo que explica que antes de ir por la indemnización, el acreedor deba pujar por el cumplimiento forzado del contrato, configurando así una verdadera jerarquía dentro del difuso sistema de remedios a favor del acreedor frustrado. 


\subsection{El artículo 1945 (artículo 2003) a la luz de la vertiente objetiva de la responsabilidad contractual, que distingue entre prestación incumplida y daño, y atribuye al acreedor el ius elections de los remedios contractuales}

Con lo dicho, entonces, podríamos colegir que el artículo 1945 (artículo 2003) constituye una expresión de la formulación clásica de la responsabilidad del deudor, labrada sobre el reproche subjetivo de su conducta que permite una cobertura indemnizatoria amplia y que, en la disyuntiva entre la disolución y la pervivencia del vínculo contractual, opta por lo último.

Lo cierto, sin embargo, es que esta intelección del precepto rápidamente convulsiona al confrontarlo con otras corrientes que informan al derecho de los contratos. Vamos por partes.

La culpa del deudor como presupuesto de esta disposición es, sin duda, la premisa que en forma más severa admite examen, lo que se explica, como afirma Suescún (2005) porque este principio se encuentra en retroceso en el derecho de contratos. La interrogante que plantea el dibujo ofrecido por la doctrina más tradicional es si la culpa responde en forma adecuada a la problemática que supone la responsabilidad contractual, particularmente bajo las actuales condiciones del tráfico. Hace más de medio siglo, en España, Puig Brutau (1957) formuló con extrema lucidez el meollo del asunto: ¿a qué vincula el contrato por su sola perfección, si luego, al sobrevenir el incumplimiento, éste, por sí solo, no constituye una base suficiente de la obligación de indemnizar?

La doctrina tradicional que objetamos responde a una concepción iusnaturalista de la relación obligatoria, que la concibe como un conjunto de deberes a cargo del deudor. Como afirma Malo (2016), esta tendencia tiende a subjetivar la relación obligatoria, reduciendo la obligación a un deber de diligencia o simple esfuerzo, que distorsiona los planos del cumplimiento material y la imputación de los perjuicios, al incardinar la culpa en ambos. El énfasis se instala en el deudor y el despliegue de deberes de conducta que, incluso, se elevan hasta constituir una causal eximente de daños.

La carga de la prueba también es alcanzada por la concepción que criticamos, pues a pesar de la claridad del artículo 1547 inciso 3 (artículo 1604 inciso 3), buena parte de la doctrina entiende que la culpa solo se presume en la medida que el acreedor demuestre en forma previa el incumplimiento material de la obligación. De este modo, la presunción de culpa solo entraría en escena en la medida que el acreedor haya probado antes la inejecución. Este esquema probatorio, además, allana el camino para que la prueba exoneratoria del deudor se satisfaga con la demostración del despliegue de un obrar diligente. En esta vertiente podemos citar, entre otros, a Domínguez Águila (2008). 
Dicha comprensión del problema que representa la carga de la prueba en la responsabilidad contractual también puede analizarse desde un punto de vista más objetivo. En dicho sentido, pensamos que el artículo 1547 inciso 3 (artículo 1604 inciso 3) no establece una auténtica presunción de culpa, sino una regla sobre carga de la prueba de la diligencia, que opera solo cuando ella juega un rol en el contenido de ciertas relaciones obligatorias, sin que de ella se pueda derivar el soporte normativo para una responsabilidad indemnizatoria de corte subjetivo.

En lo que refiere a la extensión de la cobertura indemnizatoria, los postulados de la doctrina más tradicional también admiten una relectura. Como afirman Llamas Pombo (1999) y, en Chile, Baraona (1997), Peñailillo (2009) y Contardo (2015), existen indicios que permiten inferir una diferencia sustantiva entre la prestación y su equivalente (aestimatio rei), por un lado, y la indemnización de los daños (id quod interest), por el otro, considerando que la operatividad de esta última se encuentra condicionada a la existencia de un daño objetivo, distinto y plenamente identificable de la prestación. Yzquierdo Tolsada lo resume así:

Para que surja la obligación de reparar no basta el incumplimiento de la obligación primitivamente asumida: se necesita además una lesión para los intereses de ese acreedor en beneficio del cual se encontraba configurada la relación obligatoria. La obligación de reparar no da así solución al problema que para él supone el incumplimiento de la prestación sino al problema originado cuando por ese incumplimiento se ha generado un daño en su patrimonio (1993, p. 146).

Bajo este prisma, el equivalente pecuniario no es, ni en todo ni en parte una indemnización. Este tiene lugar cuando, a pesar de encontrarse vigente la obligación, ya no es posible de cumplir en naturaleza o resulta no idónea para satisfacer el interés protegido por el contrato. En dicho caso, como dice Peñailillo (2009) la obligación subsiste, pero varía de objeto (subrogación real), debiendo el deudor pagar el precio o valor de la prestación incumplida. En otros términos, el subrogado de la prestación importa un cumplimiento por equivalencia, que constituye un cauce para la satisfacción del interés del acreedor. La indemnización, en cambio, tiene por objeto resarcir al acreedor de aquellos perjuicios que exceden del valor de la prestación incumplida, y que, por lo tanto, son consecuenciales o extrínsecos a ella. Se trata, en palabras de Llamas Pombo, "de una nueva obligación, de contenido absolutamente diferente a la originaria, que nace precisamente a causa de la generación de unos daños, a su vez debidos al incumplimiento" (1999, p. 274).

La distinción entre equivalente pecuniario y lesión del interés no envuelve una mera ficción jurídica. Por el contrario, ambos cuentan con presupuestos diferentes. La aestimatio rei exige que la prestación se haya vuelto objetivamente imposible o no idónea para los fines perseguidos por el acreedor, sin que al respecto resulten proce- 
dentes los requisitos de causalidad y previsibilidad. En cambio, el id quod interest exige la concurrencia de un nexo de causalidad entre inejecución y daño. Además, el perjuicio debe ser previsible, lo que se determina cuando su producción acaece dentro de la órbita de la distribución de riesgos controlable por el deudor, sin que este los haya excluido expresamente en el acto constitutivo de la relación obligatoria.

Por otro lado, como afirma Barros Bourie (2007), el equivalente pecuniario constituye una consecuencia automática de la imposibilidad o falta de idoneidad de la prestación -cuya prueba deberá rendir el deudor, demandado que sea el cumplimiento en naturaleza-, mientras que, respecto de los daños extrínsecos, estos deberán ser demostrados por el acreedor, sin importar las dificultades probatorias que pueda irrogar. Finalmente, cabe anotar que al momento de las excusas también existen contrastes significativos. La aestimatio rei constituye una consecuencia inmediata derivada de la inexigibilidad in natura de la obligación y, por lo tanto, no podrá el deudor asilarse en una causa extraña para sortear su pago, tal como ocurre con la prestación in natura. A lo sumo, el cumplimiento se suspenderá, pero solo mientras subsista el impedimento. Tratándose de la indemnización de los daños, en cambio, el deudor siempre podrá alegar la causa extraña, en la medida en que esta se ubique fuera de la esfera típica o de aquella en que opera el control de los riesgos, provocando la interrupción del nexo causal. Cabe agregar que el CCCh (y, consecuencialmente, el CCCo) abrigan suficiente material normativo para acoger estos planteamientos. Por de pronto, el artículo 1672 inciso $1^{\circ}\left(1731\right.$ inciso $1^{\circ}$ ) distingue perfectamente entre el "precio" de la cosa y la obligación de "indemnizar al acreedor". Similares disposiciones pueden encontrarse en las obligaciones condicionales, artículo 1486 (artículo 1543), y en las obligaciones alternativas, artículo 1502 (artículo 1559), entre otras.

Finalmente, en lo que respecta a la opción de remedios, la doctrina más reciente plantea que el acreedor tiene a su disposición un elenco de opciones, de entre las cuales puede elegir la que mejor cuadre para restablecer el interés lesionado por el incumplimiento. En esta tesitura, la preferencia por una acción no viene decidida ex ante por la ley, sino que es el acreedor quien mejor sabe, conforme a las particularidades de la relación contractual y la extensión de la lesión del derecho de crédito, cuál es la mejor vía para superar el trance que implica el incumplimiento. De este modo, quedan atrás las teorías más antiguas que ven en la realización de la obtención efectiva de lo debido la concreción más certera del principio de la fuerza obligatoria del contrato, dando paso a otras opciones igualmente válidas para la satisfacción del interés del acreedor.

Pues bien, analizadas las cosas en este contexto, en forma inmediata la duda que surge es cómo se comporta el artículo 1945 (artículo 2003) mirado bajo el prisma de las tendencias renovadoras del derecho de los contratos, y en concreto: a) si éste admite 
un enfoque objetivo, desligado de la culpa en tanto factor de imputación añadido al incumplimiento material, b) si el texto legal permite distinguir de un modo más claro la prestación de los efectos consecuenciales del incumplimiento y c) si el acreedor cuenta con un efectivo derecho de opción de remedios, sin cortapisas.

\section{El ROL DE LA CULPA EN EL ARTíCULO 1945 (ARTíCULO 2003)}

\subsection{Las obligaciones del arrendatario de cosas y la culpa}

Tanto en Chile (artículo 1915) como en Colombia (artículo 1973) el arrendamiento se define como aquel contrato "en que las dos partes se obligan recíprocamente, la una a conceder el goce de una cosa, o a ejecutar una obra o prestar un servicio, y la otra a pagar por este goce, obra o servicio un precio determinado". Existen tres clases de arrendamiento: de cosas, de obra y de servicios.

El artículo 1945 (artículo 2003) se incardina en las obligaciones del arrendatario de cosas, dentro de las cuales podemos mencionar: a) artículo 1938 (artículo 1996): el uso de la cosa según los términos convenidos o espíritu del contrato, b) artículo 1939 (artículo 1997): el empleo en la conservación de la cosa del cuidado de un buen padre de familia, c) artículo 1940 (artículo 1998): efectuar las reparaciones locativas, d) artículos 1942 a 1944 (artículos 2000 a 2002): pago del precio o renta y e) artículos 1947 a 1949 (artículos 2005 a 2007): la restitución de la cosa arrendada al fin del arrendamiento.

Los términos literales que emplea el artículo 1945 (artículo 2003) podrían llevarnos a concluir preliminarmente que su ámbito de aplicación se circunscribe a aquellas obligaciones que culpablemente pueden ser incumplidas por el arrendatario y que, por lo tanto, cuentan con un contenido subjetivo o que están referidas al empleo de un grado de diligencia o esfuerzo.

Esta interpretación exegética, sin embargo, nos obliga a desentrañar el contenido particular de cada una de las obligaciones típicas que conforman el plexo de los deberes del arrendatario de cosas. Porque si la tesitura que criticamos y hemos sometido a examen pretende erigir su coherencia, aquellas obligaciones de contenido objetivo o que supongan un resultado, deberían quedar fuera de su radio de acción, al ser innecesaria la culpa en ellas. Analicemos, entonces, las obligaciones del arrendatario de cosas.

\subsubsection{Obligación de usar la cosa según los términos convenidos o el espiritu del contrato}

La obligación de usar la cosa según los términos convenidos o espíritu del contrato no pertenece al grupo de las obligaciones de raigambre subjetiva. La identificación 
material de su contenido se circunscribe, inicialmente, al objeto convenido, cuyos contornos se encuentran regidos por la autonomía privada. De este modo, el objeto de la obligación resulta -al menos desde el punto de vista teórico- lo suficientemente preciso y acotado como para extraer de él un criterio de diligencia que sirva para establecer el momento en que la obligación se encuentra cumplida.

Solo a falta de convención expresa, el uso puede extenderse a aquellos objetos a que la cosa es "naturalmente destinada, o que deben presumirse de las circunstancias del contrato o de la costumbre del país", como señala el artículo 1938 inciso 1 (artículo 1996 inciso 1). Con todo, esta regla supletoria de integración tampoco da pábulo para aceptar la entrada del estándar de la diligencia, considerando que en forma expresa recurre a fuentes distintas para colmar el contenido de la obligación.

\subsubsection{Conservar la cosa arrendada como buen padre de familia}

A priori, el empleo en la conservación de la cosa del cuidado de un buen padre de familia pareciera responder al conjunto de obligaciones de cuya infracción emana una auténtica responsabilidad por culpa. La explicación tradicional de la conservación como prestación radica en la naturaleza misma del arrendamiento, conforme a la cual el arrendatario, al no poder disponer de la cosa, disfruta de ella, no como propietario, sino como mero tenedor. De este modo, esta obligación constituiría el corolario que impide que, al ser restituida la cosa al arrendador, este deba soportar los deterioros provocados durante la vigencia del contrato.

No obstante, con apoyo en los antecedentes históricos de la responsabilidad por custodia', de un tiempo a esta parte se ha entendido que la diligencia únicamente integra materialmente la obligación de conservar, pero no establece un régimen de responsabilidad especial, menos de carácter subjetivo² ${ }^{2}$ lo que, de un modo más amplio, incluso, también se ha dicho respecto de todas las obligaciones de hacer, sean principales o accesorias ${ }^{3}$. El contexto de la ley acude en auxilio de esta interpretación. En este sentido, el artículo 1939 inciso 2 (artículo 1997 inciso 2) in limine, al fijar las consecuencias jurídicas del incumplimiento material de la obligación de conservación, dispone: "Faltando a esta obligación, responderá de los perjuicios". Como se

1 Como destaca Betti (1969), en su origen la responsabilidad por custodia nació de una responsabilidad objetiva, dependiente del hecho de haber recibido la cosa, fundada sobre el poder de control y conservación que concierne a una cosa usualmente sometida a vigilancia, de la cual el deudor solo puede sustraerse con la prueba del suceso de fuerza mayor irresistible, que impida al deudor hacer frente al deber de restitución. En forma similar se pronuncian Guzmán Brito (1997) y Aedo Barrena (2013).

2 En esta línea se sitúa Baraona (1998). Una opinión similar puede verse en Jordano Fraga (1987). En contra, véase Cabanillas (1993).

3 En este sentido, Carrasco (2010) sostiene que el estándar de diligencia integra el contenido de la obligación en sentido objetivo y no es criterio de imputación subjetiva de la ilicitud material. 
observa, la culpa no viene exigida para la procedencia del remedio indemnizatorio; la causa se encuentra en faltar (incumplir) la obligación. La parte final del precepto ("aun tendrá derecho el arrendador para poner fin al arrendamiento, en el caso de un grave y culpable deterioro") no es un obstáculo para esta intelección, ya que la culpabilidad en cuestión debe entenderse referida a la forma omisiva que adquiere la infracción contractual (la ausencia de actos conservativos de la cosa), tal como se indica al comienzo de este inciso.

La obligación de conservar la cosa sería una obligación accesoria y autónoma respecto de aquellas de carácter principal -uso de la cosa en los términos convenidos o espíritu del contrato-, con un contenido determinado. Y, por lo mismo, la infracción de esta obligación constituye incumplimiento objetivo sin más, para lo cual no viene exigida la producción de daños consecuenciales. Así se desprende del fallo de la Corte de Apelaciones de Antofagasta de 20 de junio de 2016 (rol 147/2016), el que, pese a dejar asentado el incumplimiento de la obligación de conservación en que incurrió el arrendatario, dispuso el rechazo de la pretensión indemnizatoria, al consignar que el lucro cesante demandado no fue acreditado por el arrendador. Es decir, el incumplimiento y el daño caminan por carriles separados y producen consecuencias jurídicas diferentes. De ahí que un sector de la doctrina, en el que sobresale Baraona (1998), sostenga la eficacia de otros remedios distintos a la indemnización (cumplimiento forzado, resolución, etc.), frente al incumplimiento de esta obligación en cualquiera de sus formas.

\subsubsection{Obligación de efectuar las reparaciones locativas}

Las reparaciones locativas son otro ejemplo de obligación con contenido eminentemente objetivo. No es relevante en esta sede el esfuerzo desplegado por el arrendatario ya sea para evitar el deterioro o ejecutar la reparación una vez acaecido este. La obligación se cumple con la efectiva ejecución de los actos materiales que correspondan según la naturaleza del desperfecto sufrido por la cosa.

Tampoco afecta el diseño objetivo del deber de prestación la mayor o menor determinación del deterioro que es objeto de la reparación. En todo caso, como sugiere Meza Barros (2002), a partir del artículo 1927 inciso $2^{\circ}$ (artículo 1085 inciso $2^{\circ}$ ), es posible configurar residualmente el objeto sobre el cual recaen las reparaciones, como cualquier desperfecto que no sea constitutivo de fuerza mayor o que no provenga de la mala calidad de la cosa arrendada. Estos extremos, en todo caso, deben ser demostrados por el arrendatario que alega que ha dado cumplimiento a esta obligación. Por esta razón es correcta la sentencia de 24 de noviembre de 2016, rol 70.450-2016, conforme a la cual la Corte Suprema (2016a) rechazó el argumento del arrendatario renuente al pago de las rentas adeudadas, cuya excusa para no pagar decía relación 
con que el arrendador no efectuó reparaciones necesarias de su cargo, naturaleza que no acreditó, quedando a firme el carácter locativo de estas.

\subsubsection{Pago de la renta}

En cuanto al pago del precio o renta, no existen dificultades dogmáticas para entenderla como una obligación objetiva y, por tanto, no susceptible de valuación conforme al criterio de la diligencia. La renta, por regla general, es una obligación dineraria y, por consiguiente, insensible a la impotencia financiera del deudor, quien, consecuencialmente, debe cumplirla estrictamente en los términos estipulados. Siguiendo a Bonet (1981), el deudor, ni subjetivamente, cuando carece de dinero por su insolvencia, ni objetivamente, cuando le resulte imposible por causas materiales, puede alegar el perecimiento de la obligación de este carácter ${ }^{4}$. La obligación dineraria, complementa Larroumet (1993), es de aquellas obligaciones circunscritas a un régimen severo en lo que respecta a las excusas que puede esgrimir el deudor, ya que ni siquiera el caso fortuito es admisible como pretexto para justificar el incumplimiento. Cabe agregar, finalmente, que a falta de acuerdo convencional respecto a la cuantía y época del pago, la ley establece reglas expresas que acuden en auxilio de los contratantes, como se desprende de los artículos 1943 (artículo 2001) y 1944 (artículo 2002).

\subsubsection{Restitución de la cosa al fin del arrendamiento}

Finalmente, en cuanto a la restitución de la cosa al fin del arrendamiento, no cabe duda de que se trata de una obligación precisa, cuyo objeto no queda entregado a la discreción del arrendatario. La obligación se torna exigible con la expiración del plazo del contrato, el que por definición es futuro y cierto. El CCCh (y, desde luego, el CCCo) contiene disposiciones expresas en tal sentido, complementadas por las normas que

4 Cabe agregar que bajo este mismo predicamento, los tribunales chilenos han rechazado las excepciones opuestas por el arrendatario para evitar el pago de las rentas, cuando estas no tienen por efecto la demostración del pago. Por ejemplo, en la sentencia de 12 de octubre de 2016, rol 55.144-2016, la Corte Suprema (2016b) rechazó el recurso de casación en el fondo interpuesto por el arrendatario, quien frente a la demanda por no pago de rentas, opuso como excepción de contrato no cumplido la circunstancia de haber incumplido la arrendadora una obligación de rendición de cuenta emanada de una relación contractual paralela entre las partes. Confirmando el criterio de los jueces de la instancia, la Corte señaló que "los sentenciadores efectuaron una adecuada interpretación de las normas jurídicas pertinentes al caso, sin incurrir en la infracción denunciada, teniendo en consideración que se tuvo por acreditado el cumplimiento de la obligación del arrendador de entregar la cosa arrendada, habiendo dispuesto la demandada libremente de su tenencia, sin pagar las rentas correspondientes, por lo que la actora cumplió con su principal obligación emanada del acto jurídico celebrado. Asimismo, como las obligaciones denunciadas como incumplidas por la demandada no se vinculan con el contrato de arrendamiento que se tuvo por acreditado resulta correcta la conclusión de los sentenciadores de que por tratarse de dos actos jurídicos de naturaleza distinta correspondía desestimarla, por lo que no existió ninguna infracción al desestimar la excepción opuesta". 
regulan el estado y forma de la restitución y la constitución en mora del arrendatario -artículos 1947 (artículo 2005), 1948 (artículo 2006) y 1949 (artículo 2007)-.

\subsection{El artículo 1945 (artículo 2003) y la culpa entendida como el incumplimiento material}

Esta somera revisión de las obligaciones típicas del arrendatario nos lleva a pensar que la culpa a la cual se refiere el artículo 1945 (artículo 2003) se encuentra tomada como sinónimo de incumplimiento. Otra interpretación convertiría esta regla en una disposición prácticamente inaplicable o cuyo ámbito de aplicación se estrecharía hasta llevarla a un extremo similar, considerando que en ninguna de ellas la culpa aparece como un elemento añadido a la falta o imperfecta ejecución material. En todas ellas la culpa es el incumplimiento.

Si se analiza con detención la forma como el CCCh estructura las funciones impuestas a la diligencia, la conclusión precedente no resulta tan extraña. En efecto, a partir del examen de las disposiciones en que aparece mencionada la diligencia, ésta cumple al menos tres funciones: a) servir de mecanismo de integración del contrato, b) como factor de perpetuación de la obligación devenida imposible en forma sobrevenida y c) en fin, constituir una descripción técnica de la forma que asume el incumplimiento material. Detenerse en cada una de estas funciones excedería los márgenes de este trabajo. Por esta razón acá solo será objeto de análisis la última.

Nuestro planteamiento es que en el CCCh es posible encontrar un grupo de disposiciones en las que, tal como el artículo 1945 (artículo 2003), la culpa constituye una fórmula técnica empleada por el legislador para describir la forma que asume el incumplimiento. En todas ellas la culpa no constituye un factor de imputación que en forma adicional se adhiere al incumplimiento material. Antes que eso, en estos artículos culpa e incumplimiento equivalen a una misma y única noción. En esta dirección se ubican, entre otros, los artículos 1931 inciso 2 (artículo 1989 inciso 2), 1939 (artículo 1997), 1947 (artículo 2005), 2083 (artículo 2109), 2093 (artículo 2119), 2158 inciso final (artículo 2184 inciso final), y 2235 (artículo 2259).

Lo interesante de estas normas es la vinculación directa que plantean entre incumplimiento y perjuicios. Si se leen con atención, ninguna de las disposiciones hace de la culpa un elemento que deba añadirse al incumplimiento para sustentar el deber de indemnizar que pesa sobre el deudor.

A veces esta equivalencia se da en términos amplios, de modo tal que la voz culpa abarca todas las posibles manifestaciones de la inejecución -v. gr. artículo 1945 (artículo 2003)-. En otras disposiciones, en cambio, la culpa es solo una expresión, entre otras, de la modalidad que asume el incumplimiento. En ese bando se sitúa, por 
ejemplo, el artículo 1590 inciso 1 (artículo 1648 inciso 1), que contrapone al hecho del deudor (formulación positiva de la causa que origina el incumplimiento) la culpa de este (descripción negativa del mismo fenómeno). De esta suerte, la culpa es una modalidad del incumplimiento material, a la par del hecho. Se trata de las expresiones omisivas y positivas que constituyen las causas de un mismo fenómeno. Con todo, ambas producen los mismos efectos y constituyen (en tanto manifestaciones del incumplimiento material) el factor de imputación de daños. En esta línea se sitúan las disposiciones de los artículos 1826 inciso 2 (artículo 1882 inciso 2), 1855 (artículo 1912), 1883 inciso 2 (artículo 1941 inciso 2), 1925 inciso 1 (artículo 1983 inciso 1), 1926 (artículo 1984 inciso 1), entre otros.

Todo lo dicho trae consigo una cuestión de la más elemental importancia, porque da cuenta de que, en definitiva, el factor de atribución de los daños es el propio incumplimiento (no el incumplimiento más la culpa). Esto significa entonces que estas disposiciones específicas constituyen una manifestación de las reglas generales que regulan la indemnización de perjuicios - artículo 1556 (artículo 1613), 1557 (artículo 1615), 1558 (artículo 1616) y 1559 (artículo 1617)- las que no precisan de culpa en tanto factor de imputación y elemento distinto a la inejecución propiamente tal5.

Volviendo al supuesto de hecho del artículo 1945 (artículo 2003), podemos concluir entonces que este se encuentra conformado por el incumplimiento objetivo de cualquiera de las obligaciones contraídas por el arrendatario, esto es, cualquier desviación del programa contractual trazado por las partes en el acto constitutivo de la relación obligatoria que produzca la frustración de las expectativas del arrendador. Para ello, no es necesario un análisis del comportamiento del arrendatario o del grado de esfuerzo empleado en el cumplimiento, basta la circunstancia objetiva de la desviación de lo pactado.

\subsection{El artículo 1945 (artículo 2003) y la carga de la prueba}

Para finalizar este apartado creemos conveniente señalar que no se divisan razones que inviten a desligar el artículo 1945 (artículo 2003) de las cargas probatorias generales, ex artículo 1698 inciso 1 (artículo 1757). De este modo, la regla general es que,

5 Con todo, cabe precisar que esta equiparación entre la culpa y el incumplimiento no tiene un alcance general. Así como la diligencia solo tiene relevancia en algunos tipos contractuales -en los demás la exactitud de la prestación se determina tomando como parámetro un resultado concreto y preciso, que prescinde por completo de la valoración acerca del comportamiento del deudor, ex artículos 1569 (artículo 1627), 1590 (artículo 1648) y 1591 (artículo 1649)-, lo mismo acontece con la culpa cuando esta se asimila al incumplimiento. De ahí que la equiparación aludida solo es parcial y cobra vigor únicamente en los supuestos específicos en que la diligencia tiene alguna importancia para formar o dotar de contenido a la regla contractual. Con todo, esta comprensión acerca de la función de la diligencia no altera el fundamento de la responsabilidad del deudor, cuya base de apoyo sigue estando en la consideración objetiva del incumplimiento. 
acreditada la existencia de la obligación y alegado el incumplimiento por parte del arrendador, el peso de la prueba se traslada por completo al arrendatario, quien debe probar que cumplió o que la obligación se extinguió de otro modo, o bien que si no ha podido cumplir ha sido porque una causa extraña ha obstado a ello.

Por cierto, que la culpa de la cual habla el artículo 1945 (artículo 2003) resulte homologable al incumplimiento, descarta por completo -en sede de arrendamiento- la tesis que sostiene que el arrendador tiene la carga de la prueba del incumplimiento material y al arrendatario la prueba que desvirtúe una presunción de culpa en su contra. No hay en este caso presunción alguna que el arrendatario deba destruir. Simplemente se trata del normal juego de la carga de la prueba según el artículo 1698 inciso 1 (artículo 1757). Y así, alegado el incumplimiento, el arrendatario debe probar que cumplió, pero no para desvirtuar una presunción de culpa en su contra, sino porque de lo contrario se expondrá a sufrir el rigor de la insuficiencia probatoria por la carga que le viene impuesta ex artículo 1698 inciso 1 in fine (artículo 1757).

Las hipótesis de excepción en las que el arrendador tendrá efectivamente el peso de la prueba del incumplimiento estarán dadas por la existencia de un hecho que provenga de su esfera de acción, que permita presumir su aceptación expresa o la confirmación tácita de la regularidad del cumplimiento, lo que impondrá sobre este la prueba del incumplimiento.

Así ocurre, por ejemplo, cuando el arrendador recibe sin protesta el pago de la renta y pretende alegar en el litigio posterior que dicho pago no es eficaz. En este sentido cabe consignar el importante fallo de la Corte Suprema de 13 de julio de 2016, rol 7441-2015. En cuanto a los hechos, el arrendador demandó la terminación de un contrato de arrendamiento por el impago de las rentas. En su defensa, el arrendatario acompañó copias de los cheques que giró para el pago de las rentas, alegando la extinción de la obligación. Trasladado el riesgo probatorio al arrendador, este alegó que con dichos cheques el arrendatario solucionó deudas emanadas de una relación contractual distinta, de modo que la deuda se mantenía vigente. La Corte Suprema (2016c), conociendo del recurso de casación en el fondo interpuesto por la demandada en contra del fallo de la Corte de Apelaciones de Valparaíso, que había desestimado los argumentos del arrendatario, sostuvo:

Que, en consecuencia, el problema que corresponde dilucidar estriba en determinar quién ha incumplido su carga probatoria. El recurrente sostiene que con los cheques acompañados y cuyo importe ingresó al patrimonio del demandante, según reconoció su mandatario judicial en la vista de la causa, quedó acreditado el pago de las rentas, correspondiéndole al demandante probar que esos montos estaban destinados a solucionar una deuda diversa a los cánones de arriendo, conforme lo afirmó el propio abogado de la actora. Al no haber aportado prueba alguna respecto de este hecho 
invocado, más la prueba que los montos de los cheques fueron a parar al patrimonio del demandante, no podían los sentenciadores sin infringir el artículo 1698 del Código Civil imputarle que no se había probado el pago de las rentas. En el entendido que el propio mandatario judicial de la actora ha reconocido en estrado que los cheques fueron cobrados por su representado, lo que debe darse como un hecho establecido en la causa, y al tiempo que alegó que correspondía a una deuda diversa por otros servicios vinculados a la demandada, según lo dispuesto en el artículo 1698 del Código Civil, le correspondía haberlo acreditado. En la hipótesis que existieren diferentes deudas entre las partes, como lo aseveró el abogado de la actora, resulta pertinente el artículo 1596 del Código Civil. De acuerdo a este precepto 'si hay diferentes deudas, puede el deudor imputar el pago a la que elija; pero sin el consentimiento del acreedor no podrá preferir la deuda no devengada a la que lo está; y si el deudor no imputa el pago a ninguna en particular, el acreedor podrá hacer la imputación en la carta de pago; y si el deudor la acepta, no le será lícito reclamar después'. Bajo este supuesto, que invocó la propia actora, el deudor tenía el derecho a imputar los pagos a las rentas de arrendamiento sin que exista constancia de rechazo a la imputación por parte del arrendador. Acreditado, entonces, de que la actora ingresó a su patrimonio el importe de los cheques acompañados por la demandada por la suma de \$31.877.557, dinero que debe imputarse a las rentas adeudadas, impide considerar que el arrendatario se encontraba en mora a la época de la presentación de la demanda no resultando posible acoger el término del contrato de arrendamiento por no pago de rentas.

\section{EL FACTOR DE ATRIBUCIÓN Y LA EXONERACIÓN DE RESPONDABILIDAD DEL ARRENDATARIO. LA FUNCIÓN DE LA INDEMNIZACIÓN COMO REMEDIO CONTRACTUAL}

Esta dirección del artículo 1945 (artículo 2003) plantea adicionalmente otras interrogantes. El inciso $1^{\circ}$ previene que frente al incumplimiento (objetivo) de cualquiera de las obligaciones del arrendatario, este será obligado a la indemnización de perjuicios, especialmente al pago de la renta de arrendamiento hasta el término del contrato.

La cuestión estriba en esclarecer el posible conflicto entre dos extremos: primero, el supuesto de hecho, de naturaleza objetiva, y los requisitos de la indemnización, asociados tradicionalmente al incumplimiento culposo. Este aspecto, además, nos llevará a analizar las causales eximentes de responsabilidad del deudor. La otra interrogante se refiere a la función de la indemnización como remedio para el contratante insatisfecho. En concreto, la pregunta es si el artículo 1945 inciso $1^{\circ}$ (artículo 2003 inciso $1^{\circ}$ ) abriga una auténtica indemnización o si, con más propiedad, el valor de la prestación constituye una noción autónoma respecto del resarcimiento.

\subsection{El fundamento de la responsabilidad y las causales de exoneración del arrendatario}

Lo que corresponde dilucidar es si en el artículo 1945 (artículo 2003) la culpa es el factor de imputación de los daños y cuáles son las formas de liberación de responsabilidad que puede esgrimir el deudor. 
En cuanto al primer aspecto, hemos adelantado que un sector de la doctrina sostiene que en el sistema general de responsabilidad contractual la culpa no forma parte del supuesto de hecho del incumplimiento, lo que descartaría que sirva además como factor de imputación. Por lo tanto, la cuestión consiste en determinar si el artículo 1945 (artículo 2003) se aparta de este principio o si, por el contrario, importa una aplicación de él.

La lectura tradicional, liderada por Alessandri, plantea que en este caso el factor de imputación es subjetivo. Y así:

Cuando la terminación del arrendamiento se produce a causa de culpa del arrendatario, por haber infringido las disposiciones que el contrato le impone, el arrendatario queda obligado a indemnizar al arrendador de todos los perjuicios, y lo que es más grave, a pagar la renta conforme al artículo 1945 (1988, p. 173).

Otros autores, como Barros Errázuriz (1932), son menos explícitos, limitándose a transcribir el texto de la norma. La jurisprudencia suele razonar de este modo. Por ejemplo, en la sentencia de 18 de octubre de 2016, rol 34.176-2017, la Corte Suprema resolvió:

Que, como se indicó, la sentencia acogió la demanda y ordenó el pago de las rentas devengadas hasta la fecha de vigencia originalmente pactada, tras calificar de improcedente el término anticipado del contrato efectuado por la demandada, por haberse producido en un supuesto de hecho distinto del previsto para el caso. Los razonamientos desarrollados por los jueces del fondo desarrollan los motivos por los cuales el término unilateral resultó improcedente a la luz de lo pactado por las partes y el cumplimiento de sus obligaciones por parte del arrendador, lo que importa que deba presumirse culpable el actuar consistente en su término anticipado sin existir una causal que lo habilite para ello, quedando obligado a reparar los perjuicios causados al contratante diligente. Así, en base a los hechos establecidos en el proceso, que dan cuenta del actuar diligente de una parte y culpable de la otra, y que no han sido objeto de impugnación por esta vía al no denunciar la infracción a normas reguladoras de la prueba, lo que los torna en inamovibles para esta Corte, sólo cabe concluir que lo resuelto se aviene íntegramente con lo previsto en la norma cuyo quebrantamiento se acusa, la que, en consecuencia, ha sido correctamente aplicada.

Por nuestra parte, creemos que existen mejores razones para sostener que la indemnización de perjuicios tiene como presupuesto el incumplimiento objetivo de las obligaciones del arrendatario, siendo éste (y no la culpa), el factor de atribución de los daños.

Para abonar esta conclusión hay que recordar que el supuesto de hecho se encuentra afirmado en todos los casos por el incumplimiento de cualquiera de las obligaciones del arrendatario, sin que el error de conducta del deudor constituya un elemento 
adicional de la inejecución que deba tenerse en cuenta. Lo mismo podemos afirmar en los casos en que la diligencia sirve como presupuesto material de la prestación, como ocurre con la obligación de conservación de la cosa.

No existe en el artículo 1945 (artículo 2003) ningún elemento para sostener que el incumplimiento se encuentra conectado con la negligencia y que sea esta la razón última de la imposición del deber de indemnizar. Muy por el contrario, una lectura detenida del precepto nos obliga a concluir que la conexión causal ocurre a nivel del incumplimiento material ("será el arrendatario obligado a la indemnización"), siguiendo el principio sentado en el artículo 1556 (artículo 1613). De este modo, parece clara la eficacia de la inejecución para desencadenar la reacción jurídica contra los daños.

Respecto a las causales de exoneración, no siendo la culpa el factor de imputación entendemos que la extensión de la responsabilidad del arrendatario llega hasta la concurrencia de una causa extraña que tenga por efecto producir una interrupción del nexo causal entre inejecución y daño.

En este sentido, parece más acertada en esta parte la sentencia de la Corte Suprema de 5 de julio de 2018, rol 45.626-2017, que rechazó la casación en el fondo deducida por el arrendatario en contra del fallo de la instancia que acogió la demanda por no pago de rentas, sobre la base del abandono del inmueble perpetrado por este último. En el considerando en el cual se pronuncia sobre la supuesta infracción al artículo 1945 (2003), señala que:

Sobre la base de los hechos establecidos en la sentencia impugnada, inamovibles para este tribunal de casación, pues no fueron materia del recurso, ya que no se denunció la conculcación de las denominadas normas reguladoras de la prueba, debe desestimarse su vulneración, toda vez que la recurrente reconoce que abandonó el inmueble antes de la fecha pactada para la conclusión del contrato, añadiendo que se debió a las pérdidas que experimentó, circunstancia que, naturalmente, no puede ser imputada a su contraparte, ni configura una hipótesis de caso fortuito o fuerza mayor, de modo que la arrendataria aparece como la única responsable del éxito o fracaso de su emprendimiento comercial y de las consecuencias que de ello se deriven.

Cabe consignar además que el artículo 1941 (1999) dispone expresamente que: "el arrendatario es responsable no sólo de su propia culpa, sino de la de su familia, huéspedes y dependientes", con lo cual esta teoría cuenta además con un soporte normativo para sustentar la responsabilidad del arrendatario por los hechos de sus dependientes, sin que la culpa de la cual habla el precepto se deba entender referida a un factor de reproche anejo al incumplimiento, sino, precisamente a este último. 


\subsection{La función de la responsabilidad contractual en el arrendamiento de cosas}

En lo que se refiere al segundo aspecto, entendemos que en el artículo 1945 (artículo 2003) existen buenos argumentos para sostener -en consonancia con otras disposiciones del CCCh, como el artículo 1672 inciso $1^{\circ}$ (artículo 1731 inciso $1^{\circ}$ )- la distinción entre la prestación (y eventualmente, su equivalente) y la indemnización de los daños que excedan de ella (id quod interest).

En efecto, a partir de la literalidad del inciso 1, es posible distinguir con claridad entre la indemnización de los daños contractuales ("será el arrendatario obligado a la indemnización de perjuicios") de la prestación en sí misma ("y especialmente al pago de la renta por el tiempo que falte hasta el día en que desahuciando hubiera podido hacer cesar el arriendo, o en que el arriendo hubiera terminado sin desahucio"). La conjunción "y" que utiliza el precepto debiera despejar cualquier asomo de duda. La renta en la mayoría de los casos consistirá en dinero, es decir, una obligación de género; por lo mismo, su pago ex artículo 1945 (artículo 2003) no constituye un subrogado, sino la obligación misma. Pero si ésta, de acuerdo al contrato, debe ser pagada con los frutos naturales de la cosa arrendada u otra modalidad semejante, nada obsta a que ante una imposibilidad sobrevenida provocada por el arrendatario que impida el pago, la obligación no solo no se extinga, sino que se perpetúe con su equivalente pecuniario (valor de la prestación).

En apoyo de esta tesis se encuentra la redacción del inciso 2 -que analizaremos en el apartado siguiente-, que permite eximir al arrendatario del pago de la renta proponiendo a una persona idónea que le sustituya por el tiempo que falte en su lugar jurídico, disposición que no tendría ningún sentido si la naturaleza de aquella fuera únicamente indemnizatoria. En efecto, dada la naturaleza fungible del resarcimiento, nada debería impedir el pago hecho por un tercero sin necesidad de consentimiento del acreedor.

En fin, también está la disposición del artículo 1917 (artículo 1975), que establece perentoriamente que la renta de arrendamiento - llamada así cuando se paga periódicamente- es, a los efectos de la contraprestación por el uso de la cosa, el precio del contrato, según el artículo 1915 (artículo 1793).

De este modo, entendemos que el artículo 1945 (artículo 2003) debe leerse en el sentido que, declarada la terminación del contrato por incumplimiento del arrendatario, este es obligado al pago del precio del contrato por el período que reste ${ }^{6}$

6 En la legislación especial sobre arrendamiento de predios urbanos (Ley 18.101, de 29 de enero de 1982), el artículo $6^{\circ}$ dispone: "cuando el arrendamiento termine por la expiración del tiempo estipulado para su duración, por la extinción del derecho del arrendador o por cualquier otra causa, el arrendatario 
y, además, a la indemnización de los daños consecuenciales al incumplimiento, que sean causalmente reconducibles a la inejecución ${ }^{7}$. Respecto del pago de la renta, no se exigirá más prueba al acreedor que la de la existencia de la obligación, mientras que, en cuanto a los daños consecuenciales, estos requerirán la prueba de la causalidad y previsibilidad. En todo caso, como recuerda Cornejo (2012), si producida la terminación el arrendador logra celebrar un nuevo contrato, el arrendatario primitivo puede solicitar la restitución de aquellas rentas pagadas y que de otro modo constituirían un enriquecimiento sin causa para aquel.

\section{LA OPCIÓN DE REMEDIOS Y EL ARTÍCULO 1945 INCISO 2 (ARTÍCULO 2003 INCISO 2)}

Resta aún el análisis del artículo 1945 inciso $2^{\circ}$ (artículo 2003 inciso $2^{\circ}$ ). Como hemos visto, después de establecer que la terminación del contrato por incumplimiento del arrendatario lo obliga a la indemnización y al pago de las rentas faltantes, el precepto en cuestión dispone que "podrá con todo eximirse -el arrendatario- de este pago proponiendo bajo su responsabilidad persona idónea que le substituya por el tiempo que falte, y prestando al efecto fianza u otra seguridad competente". A partir de lo señalado surgen algunas interrogantes. La primera es si esta norma envuelve una limitación frente a la opción de remedios del acreedor por incumplimiento. Esclarecido lo anterior, la segunda dice relación con las condiciones de procedencia de la sustitución. En lo que sigue intentaremos dar respuesta a ambas cuestiones.

continuará obligado a pagar la renta de arrendamiento y los gastos por servicios comunes que sean de su cargo, hasta que efectúe la restitución del inmueble". De esta forma, se ha entendido reiteradamente que en materia de arrendamiento de inmuebles, la pretensión del arrendador que reclama el pago de rentas impagas, se limita a aquellas que se han devengado con anterioridad a la fecha en que se acredite la restitución de la propiedad. En este sentido, la Corte Suprema (2016e), por sentencia de 3 de octubre de 2016, rol 49.965-2016, señaló: "que del examen de la sentencia impugnada se concluye que los sentenciadores se ajustaron a lo dispuesto en el citado el artículo $6^{\circ}$ de la Ley 18.101, que establece la obligación de continuar pagando la renta acordada con el antiguo dueño, hasta su restitución, como una forma de evitar el enriquecimiento sin causa, que significaría la ocupación del inmueble en forma gratuita y, por otro lado, percibir rentas de un inmueble del que se puede disponer materialmente, como ocurrió en el caso de autos".

7 Por lo mismo, solo compartimos parcialmente lo resuelto por la Corte Suprema (2016d). En los hechos, el acreedor/arrendador demandó el pago de las rentas adeudadas hasta la fecha en que el deudor/ arrendatario restituyó anticipada y voluntariamente el inmueble arrendado, y, a título de "indemnización de perjuicios", aquellas rentas que faltaban hasta completar el período estipulado en el contrato. No obstante confirmar lo resuelto por la Corte de Apelaciones de Santiago, que revocó la negativa del juez del fondo en orden a acceder al pago de las rentas hasta el término del contrato, el máximo tribunal entendió que la naturaleza de lo pedido correspondía a una indemnización de perjuicios fundada en la culpa. Así, en el considerando cuarto, señaló: "Que, en lo que dice relación con las alegaciones referidas precedentemente, cabe señalar que no se advierten las infracciones de ley acusadas, toda vez que, de conformidad a lo dispuesto en el artículo 1945 del Código Civil, nace para el arrendatario la obligación de indemnizar perjuicios cuando el contrato de arrendamiento expira por culpa suya, siendo procedente el pago de las rentas por el tiempo que falte hasta su terminación". 


\subsection{La opción de remedios y la sustitución del arrendatario como límite a la facultad resolutoria del contrato}

Sobre este punto no existen mayores referencias en la doctrina chilena. De la lectura de la obra de Cornejo parecería desprenderse la conclusión de que, efectivamente, la sustitución propuesta por el arrendatario constituye un límite al ejercicio de la resolución ${ }^{8}$ del contrato por incumplimiento sus obligaciones, "cuestión que se explica si consideramos que manteniéndose la relación contractual con una nueva parte arrendataria, el arrendador no experimentará perjuicio alguno, máxime si las obligaciones que el nuevo arrendatario contraiga serán garantizadas por el arrendatario primitivo" (2012, p. 239). Esto querría decir que aun cuando el arrendador haya optado por la resolución, estaría obligado a la continuidad del contrato, ante la propuesta de sustitución formulada por el arrendatario primitivo, cumpliéndose con las restantes exigencias previstas en el artículo 1945 inciso 2 (artículo 2003 inciso 2).

En la sentencia de la Corte Suprema de 5 de julio de 2018, rol 45.626-2017, ya citada, aun cuando no hay un pronunciamiento directo sobre la materia, pareciera desprenderse la idea de que basta con que el arrendatario proponga al sustituto para que el arrendador venga constreñido por esa designación?

En el derecho uniforme de los contratos, recuerda Sánchez (2016), la opción de remedios básicamente viene afirmada como un sistema libre, que en última instancia dependerá del tipo de incumplimiento producido, esencial o no, de que el incumplimiento esté o no justificado y de que no haya contribuido en todo o en parte el acreedor a causar el incumplimiento. Quien elige es el acreedor, salvo que se trate del derecho del deudor para subsanar el incumplimiento.

Por nuestra parte, creemos que no existen razones para afirmar que el artículo 1945 inciso 2 (artículo 2003 inciso 2) contiene una verdadera limitación al derecho de opción, que imponga al arrendador la pervivencia del contrato, cuando este ha optado previa y definitivamente por la resolución. En efecto, la ley expresamente señala que el arrendatario puede eximirse del pago de las rentas restantes "proponiendo" a una persona idónea. Proponer, conforme al diccionario de la RAE, consiste en "manifestar con razones algo para conocimiento de alguien, o para inducirle a adoptarlo". Pero la autorización y aceptación de la propuesta recaerán siempre en el propio arrendador, quien eventualmente puede esgrimir causas justificadas para rechazarla.

8 Hacemos presente que en Chile la resolución en contratos de tracto sucesivo, como el arrendamiento, se denomina "terminación".

9 En efecto, en relación con la supuesta infracción a esta norma, la Corte Suprema (2018) señala que: "en lo relativo al supuesto previsto en el inciso segundo de la norma citada, el fallo cuestionado no dio por acreditado que la arrendataria haya propuesto una persona idónea que la substituyera en el contrato, por lo que se trata de un argumento que contraviene el sustrato fáctico de la decisión, lo que impide que pueda prosperar". 
La más relevante, a nuestro entender, dirá relación con la falta de confianza en la persona del arrendatario original, quien, de acuerdo a la disposición citada, formula la propuesta "bajo su responsabilidad", prestando "fianza u otra seguridad competente". Puede ocurrir que su situación patrimonial se encuentre desmejorada, o que de cualquier modo resulte previsible que su responsabilidad o las garantías que ofrezca no podrán hacerse efectivas, de todo lo cual -por cierto- el incumplimiento que motivó la resolución constituirá un hecho revelador. En dicho caso, si la asunción de responsabilidad por parte del arrendatario original y las garantías ofrecidas no satisfacen las expectativas del arrendador, este no podrá ser forzado a aceptar la sustitución del arrendador por un tercero.

Si, por el contrario, el arrendador acepta las garantías, el contrato continuará con la persona del nuevo arrendatario, en sustitución del anterior. En este supuesto, se tratará del mismo contrato, no de un nuevo vínculo, sin perjuicio de que así lo convengan los interesados.

Además, existe otra poderosa razón. Si prestamos atención a la configuración de la novación por cambio de deudor, podremos advertir que esta requiere del consentimiento del acreedor, a quien, desde luego, no le resultará indiferente la persona del sujeto pasivo de la obligación. En este caso, no se vislumbran razones para sostener que en un contrato de tracto sucesivo, o sea donde la vinculación entre las partes se prolonga en el tiempo, el CCCh se haya apartado de dicho principio. Por lo mismo, parece más acorde con la sistemática general del CCCh la comprensión que pone en el acreedor/arrendador la facultad para aceptar o rechazar la propuesta del deudor/ arrendatario primitivo.

De esta forma, la aceptación del sustituto propuesto sigue siendo un derecho privativo del arrendador, quien podrá denegarlo justificadamente, esgrimiendo que la resolución constituye el mejor cauce para la satisfacción de sus intereses.

\subsection{Las condiciones de procedencia de la sustitución del arrendatario primitivo}

Antes que todo debemos considerar que la aprobación del arrendador solo es exigible cuando le es propuesto un nuevo arrendatario para que ocupe el lugar jurídico del primitivo y pague las rentas restantes. De este modo, la autorización del arrendador no será necesaria en cuanto al pago de la indemnización, puesto que, en principio, nada impediría que un tercero pague dicha suma, al ser una obligación con objeto fungible.

Otro aspecto que cabe tener en cuenta es que para que se produzca la sustitución, el arrendatario original debe otorgar una "fianza u otra seguridad competente". 
Ya que el precepto no distingue, estas garantías pueden ser propias del arrendatario o provenir de un tercero que las constituya. Es probable que esta última sea la situación más frecuente y aconsejable, considerando que, al haber incumplido la obligación primigenia, lo normal será que el arrendador desconfíe de la solvencia del arrendatario original.

Finalmente, la ley previene que la sustitución del arrendatario opera "bajo su responsabilidad", con lo cual surge la interrogante respecto al alcance de esta expresión. Sobre este punto, el artículo 1635 (artículo 1694) señala: "la substitución de un nuevo deudor a otro no produce novación, si el acreedor no expresa su voluntad de dar por libre al primitivo deudor. A falta de esta expresión, se entenderá que el tercero es solamente diputado por el deudor para hacer el pago, o que dicho tercero se obliga con él solidaria o subsidiariamente, según parezca deducirse del tenor o espíritu del acto".

Conforme a lo anterior, pareciera existir un argumento de texto para sostener que el arrendatario primitivo, al no quedar expresa y totalmente liberado, puede constituirse como un mandatario para el pago de las rentas, o bien entenderse que se ha establecido como deudor solidario o subsidiario. A falta de estipulación, creemos que el arrendatario primitivo solo será un mandatario de su sustituto para el pago de las rentas. De este modo, tal como ocurre con el régimen común, según recuerda Vial (2007), para que operen la solidaridad o la subsidiaridad, se requerirá de una cláusula expresa que las establezca.

\section{CONCLUSIONES}

El supuesto de hecho del artículo 1945 (artículo 2003) está constituido por el incumplimiento objetivo de cualquiera de las obligaciones impuestas por el contrato de arrendamiento al arrendatario.

El factor de imputación de los daños cuya reparación ordena el precepto se construye a partir del incumplimiento material del contrato, no existiendo razones para referirlas a la culpa del arrendatario. En todo caso, para que surja la obligación de indemnizar, los daños deben estar conectados causalmente con el incumplimiento y ser previsibles conforme al entramado de riesgos que distribuye el contrato. En cuanto a las excusas, nada impide que el arrendatario alegue una causa extraña que interrumpa el nexo causal.

Las consecuencias jurídicas del incumplimiento de las obligaciones del arrendatario están constituidas por el pago del precio del contrato por el período restante, 
así como por la indemnización de los daños consecuenciales. El primero es el mismo valor de la prestación, que constituye una consecuencia automática de la inejecución, del que no se predican las exigencias de causalidad y previsibilidad que, en cambio, sí vienen exigidas para los perjuicios.

El artículo 1945 inciso $2^{\circ}$ (artículo 2003 inciso $2^{\circ}$ ) no envuelve una limitación al derecho de opción que la ley reconoce al acreedor/arrendador por el incumplimiento. En consecuencia, este puede oponerse a la propuesta efectuada por el arrendador para que una persona le substituya, si se ha manifestado por la terminación definitiva del vínculo contractual.

\section{REFERENCIAS}

Abeliuk Manasevich, R. (2001). Las obligaciones. Santiago de Chile: Editorial Jurídica de Chile.

Aedo Barrena, C. (2013). La responsabilidad por custodia: ¿̇responsabilidad estricta o por culpa? En A. Mondaca y C. Aedo (Coords.), Nuevos horizontes del derecho privado (pp. 25-56). Santiago de Chile: Librotecnia.

Alessandri Rodríguez, A. (1930). Teoría general de las obligaciones. Santiago de Chile: Cisneros.

Alessandri Rodríguez, A. (1988). De los contratos. Santiago de Chile: Editorial Jurídica Ediar Conosur.

Baraona González, J. (1997). Responsabilidad contractual y factores de imputación de daños: apuntes para una relectura en clave objetiva. Revista Chilena de Derecho, 24(1), 156-162.

Baraona González, J. (1998). El retraso en el cumplimiento de las obligaciones. Madrid: Dykinson.

Barros Bourie, E. (2007). La diferencia entre estar obligado y ser responsable en el derecho de los contratos. En H. Corral y M.S. Rodríguez (Coords.), Estudios de Derecho Civil II (pp. 721-752). Santiago de Chile: LexisNexis.

Barros Errázuriz, A. (1932). Curso de derecho civil (segundo año, segunda parte, vol. III). Santiago de Chile: Editorial Nascimento.

Betti, E. (1969). Teoría general de las obligaciones (Trad. José Luis de los Mozos). Madrid: Editorial Revista de Derecho Privado.

Bonet Correa, J. (1981). Las deudas de dinero. Madrid: Civitas.

Cabanillas Sánchez, A. (1993). Las obligaciones de actividad y de resultado. Barcelona: José María Bosch Editor.

Capilla Roncero, F. (1989). La responsabilidad patrimonial universal y el fortalecimiento de la protección del crédito. Jeréz: Fundación Universitaria de Jeréz.

Carrasco Perera, Á. (2010). Derecho de contratos. Cizur Menor: Thomson Reuters. 
Chile. Corte de Apelaciones de Antofagasta. (2016). Román Serra con Conveyor Services S. A. Rol $\mathrm{N}^{\circ} 147-2016$.

Claro Solar, L. (1937). Explicaciones de derecho civil chileno y comparado. De las obligaciones (tomo XI). Santiago de Chile: Nascimento.

Colombia. Congreso de la República. (1873). Código Civil. Recuperado de http://www.secretariasenado. gov.co/senado/basedoc/codigo_civil.html

Contardo González, J.I. (2015). Indemnización y resolución por incumplimiento. Santiago de Chile: Thomson Reuters.

Cornejo Aguilera, P. (2012). El contrato de arrendamiento de bienes raíces urbanos. Santiago de Chile: LegalPublishing.

Corte Suprema de Chile. (2018). Inversiones e Inmobiliaria Celimitada con Comercializadora Don Jorge y Compañía Limitada. Rol 45.626-2017. Casación en el fondo.

Corte Suprema de Chile. (2016d). San Miguel y Compañía Limitada con Calvo Castro. Rol 49.965-2016. Casación en el fondo.

Corte Suprema de Chile. (2016a). Curín Reinante con San Miguel Uribe. Rol 70.450-2016. Casación en el fondo.

Corte Suprema de Chile. (2016b). Banco Santander Chile con Starry Night Vineyard Limitada. Rol 55.144-2016. Casación en el fondo.

Corte Suprema de Chile. (2016c). Inversiones ISV S. A. con Dina Soto Campos Productos Ópticos E.I.R.L. Rol 7441-2015. Casación en el fondo.

Corte Suprema de Chile. (2016d). López Paulus con Manzárraga y otro. Rol 34.042-2016. Casación en el fondo.

Corte Suprema de Chile. (2017). Pareti Campodónico con Junta Nacional de Jardines Infantiles. Rol 34.176-2017.Casación en la forma y en el fondo.

Cortés, É. (2009). La culpa contractual en el sistema jurídico latinoamericano. Bogotá: Universidad Externado de Colombia.

Cristóbal Montes, Á. (1989). El incumplimiento de las obligaciones. Madrid: Tecnos.

Domínguez Águila, R. (2008). La culpa en el derecho civil chileno. Aspectos generales, Revista Anales Derecho UC, Temas de Responsabilidad Civil, 3, 116-126.

Fueyo Laneri, F. (1958). Derecho Civil. De las obligaciones (vol. I tomo IV). Santiago de Chile: Universo.

García Vásquez, D. (2014). Condición resolutoria tácita y responsabilidad del deudor: dos remedios complementarios y autónomos contra el incumplimiento. Bogotá: Universidad Externado de Colombia. 
Guzmán Brito, A. (1997). La responsabilidad objetiva por custodia en el derecho romano y en el derecho moderno, con una referencia especial a la regla periculum est emptoris. Revista Chilena de Derecho, 24(1), 179-199.

Jordano Fraga, F. (1987). La responsabilidad contractual. Madrid: Civitas.

Larroumet, C. (1993). Teoría general del contrato (vol. II., Trad. Jorge Guerrero R). Bogotá: Temis.

Llamas Pombo, E. (1999). Cumplimiento por equivalente y resarcimiento del daño al acreedor. Entre la aestimatio rei $y$ el id quod interest. Madrid: Trivium.

López Díaz, P. (2015). La autonomía de la indemnización de daños por incumplimiento de un contrato bilateral en el Código Civil chileno. Santiago de Chile: Thomson Reuters.

Malo Valenzuela, M.A. (2016). Remedios frente al incumplimiento contractual. Derecho español, derecho inglés y Draft Common Frame of Reference. Cizur Menor: Aranzadi.

Meza Barros, R. (2002). Manual de derecho civil. De las fuentes de las obligaciones (tomo I). Santiago de Chile: Editorial Jurídica de Chile.

Ospina Fernández, G. (2016). Régimen general de las obligaciones. Bogotá: Temis.

Peñailillo Arévalo, D. (2009). Responsabilidad contractual objetiva. En C. Pizarro (Coord.), Estudios de Derecho Civil IV (pp. 331-346). Santiago de Chile: LegalPublishing.

Puig Brutau, J. (1957). Comentario del traductor. En Lon L. Fuller y W. R. Perdue (Eds.), Indemnización de los daños contractuales y protección de la confianza (pp. 143-182). Barcelona: Bosch.

República de Chile. (2000). Código Civil. Recuperado de https://www.leychile.cl/Navegar?idNorma= 172986 EidParte $=8717776$

Sánchez Ruiz de Valdivia, I. (2016). El sistema de remedios por incumplimiento en los textos europeos de referencia. Revista Doctrinal Aranzadi Civil-Mercantil, 7, 65-92.

Suescún Melo, J. (2005). Derecho privado. Estudios de derecho civil y comercial contemporáneo (tomo I). Bogotá: Legis.

Tamayo Jaramillo, J. (1990). Culpa contractual. Bogotá: Temis.

Uribe-Holguín, R. (1979). Cincuenta breves ensayos sobre obligaciones y contratos. Bogotá: Temis.

Vial del Río, V. (2007). Manual de las obligaciones en el Código Civil chileno. Santiago de Chile: Editorial Biblioteca Americana.

Yzquierdo Tolsada, M. (1993). Responsabilidad civil contractual y extracontractual. Madrid: Reus. 